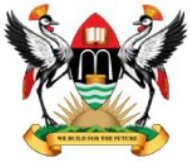

East African School of

Higher Education Studies \& Development

\title{
Entrepreneurial Awareness and Skills in Mechanical Technology among Technical Education Students in Tai Solarin University of Education
}

\author{
Lemo Olusiji Olaseni $^{1, *}$, Olakotan Olusegun Olawale ${ }^{1}$ \\ ${ }^{1}$ Department of Technical Education, Tai Solarin University of Education [*Corresponding \\ author: rossandlemo@yahoo.co.uk]
}

\begin{abstract}
This study assessed entrepreneurial awareness and skills in Mechanical Technology among Technical Education Students in Tai Solarin University of Education. Research questions focusing on the students' level of entrepreneurial awareness and the facilities available for inculcating skills in Mechanical Technology guided the study. A 38-item self-developed questionnaire entitled "Assessment of Entrepreneurial Awareness Questionnaire" (AEAQ) was used to collect data from 22 respondents. The questionnaire was validated by three experts and its reliability coefficient was established at .89 using Cronbach's Alpha Coefficient method. The data collected were analysed using descriptive statistics. The study applauded the management of the University for providing an enabling environment for Mechanical Technology students to acquire entrepreneurial skills. The study recommended, among others, that the students embrace this opportunity that the University is giving them.
\end{abstract}

Keywords: Entrepreneurship; Curriculum innovation; STEM.

\section{$1 \quad$ Introduction}

Mechanical Technology is an integration of two different areas of specialization in Technical Education. It is a combination of both Automobile Technology and Metalwork Technology. Automobile Technology equips recipients with knowledge and skills in automobile maintenance, repairs and troubleshooting while Metalwork Technology equips recipients with skills and knowledge in forming, cutting, joining and machining among others. Since there are similarities in Automobile Technology and Metalwork Technology, some institutions of higher learning offering Technical Education prefer the integration of these areas for convenience sake. 
Elisha, (2014) stated that Mechanical Technology is an integral part of Technical Education, which was introduced into the Nigerian education system because of the awareness of its importance and opportunities for jobs creation.

Technical Education according to Lemo and Olakotan (2016) has a component of five different areas of specializations namely: Automobile Technology, Building Technology, Electrical/Electronic Technology, Metalwork Technology and Woodwork Technology and that each student is expected to specialize in one of these areas after having an all-round knowledge of all the components of the programme. Uwaifo (2009) posited that Technical Education is the training of technically oriented personnel who are to be the initiators, facilitators and implementers of technological development of a nation. This view of Technical Education relates its recipients to initiators which is one of the major characteristics of an entrepreneur.

An entrepreneur according to Lidimma (2012) is a giver of employment, provider of infrastructures and valuable services to the community. Aminu (2009) posited that the success of an entrepreneur is dependent on his determination, leadership quality, creativity, self-nurturing, self-discipline, energetic, future oriented among other notable characteristics.

Entrepreneurship is of paramount importance to our society. Entrepreneurs contribute to economic welfare as they increase the innovative capacity of the economy. Timmons and Spinelli (2004) refer to entrepreneurship as a way of thinking, reasoning and acting that is opportunity- based, holistic in approach and leadership balanced. Entrepreneurship results in the creation, enhancement, realization and renewal of value not just for the owners, but for participants and stakeholders.

Entrepreneurship however, in the context of this study as used by Nwoye (2011) is the process of identifying, developing and bringing a vision to life. The vision may be an innovative idea, an opportunity, or simply a better way to do something.

Dyke, Fischer and Rueber, (1992) provides an entrepreneurial framework on which this present study rests. Dyke et al posited that human capital entrepreneurial characteristics like their education level, work experience, startup experience, training and skills and technical know-how determine whether an entrepreneur possesses the appropriate abilities, the possession of which in turn affects his or her decision to start up the business and also its success.

Since Technical Education can boast of five different areas of specialization, it of utmost importance to assess the students' entrepreneurship awareness and the skills possessed in order to correlate the findings of this study to the goals of VTE in general.

Assessment is expressing opinions using degrees or descriptive feedback. It can be carried out occasionally or regularly, during or after the activity. Assessment serves several purposes. It gives information about the knowledge, 
skills and attitude students have acquired. Assessment on the other hand determines merit, worth and significance of a programme. This means that, it provides objective means of monitoring the progress of an individual in a programme. Academic Exchange Quarterly, (AEQ) (2009) stated that assessment is the process of documenting, usually in measurable terms, knowledge, skill attributes and believes. Assessment can focus on facilities, or the educational system as a whole.

On the other hand, facilities are required in all Technical and Vocational Institutions to enable easy passage of knowledge and skills to students. These facilities are both human and material. Human facilities as used in this study are lecturers (Automobile and Metalwork), and technologists while material facilities are workshop, tools, machines, consumables, and other equipment provided in the TVE institutions for the purpose of enhancing teaching and learning processes towards attainment of entrepreneurship state.

Elisha (2014) avowed that despite the high expectation of the society of mechanical technology graduates to achieve self-reliance, their performance is on the decline. He noted that some of the problems being faced in this area are high cost of tools and equipment needed for setting up metal workshops, hence, a high percentage of metal workshops operate on obsolete tools and equipment, inadequately trained technical instructors, inadequate funds for consumables, and workshop facilities. Afeti (2007) stated that, the quality of training in TVE institutions in Nigeria is low with undue emphasis on theory and certification rather than on skills acquisition and proficiency testing. He further noted that inadequate instructor training, obsolete training equipment and lack of instructional materials are some of the factors that combine to reduce the effectiveness of training in meeting the required knowledge and skill objectives. Similarly, Oputa (2008) pointed out that functional facilities enable schools and society to achieve their educational goals. Therefore, assessment of entrepreneurship awareness and skills in mechanical technology among technical education students may be inconclusive if facilities needed for the passage of entrepreneurial skills are jettisoned. Hence, this study becomes significant.

\subsection{Statement of the Problem}

The assertion that if the purpose of a thing is unknown, abuse is inevitable necessitates this study. This premise spurred the researchers to carefully observe Mechanical Technology graduates who seems not to understand the components of entrepreneurship in Technical Education and similarly do not know the stuff they are made of. Hence, they pursue after white collar jobs that are not readily available neglecting their call to entrepreneurship which mechanical technology in Technical Education programme offers. 


\subsection{Purpose of Study}

This study assessed entrepreneurial awareness and skills in mechanical technology among technical education students in Tai Solarin University of Education. Specifically, the study sought to determine:

1. Students' levels of entrepreneurial awareness in Mechanical Technology

2. Skills expected by Technical Education students for entrepreneurship in Mechanical Technology

3. Facilities available for inculcating entrepreneurial skills in Mechanical Technology

\subsection{Research Questions}

1. What are the students' levels of entrepreneurial awareness in Mechanical Technology?

2. What are the skills expected by Technical Education students for entrepreneurship in Mechanical Technology?

3. What are the facilities available for inculcating entrepreneurial skills in Mechanical Technology?

\section{$2 \quad$ Methodology}

\subsection{Design}

This study adopted a descriptive survey research design. According to Gall, Gall and Borg (2007) a survey is a method of data collection using questionnaire or interviews to collect data from a sample that has been selected to represent a population to which the findings of the data analysis can be generalized. Hence the questionnaire on assessment of entrepreneurial awareness and skills among technical education students in Tai Solarin University of education was used to collect data from the population for analyses. The design was considered suitable for the study since it sought the opinions of Technical Education students and no variable was manipulated.

\subsection{Population}

The population of the study was all the 22 final year Technical Education students of Tai Solarin University of Education, Ijebu-Ode. All of them were involved in the study because the number was small and manageable. 


\subsection{Instrument}

Assessment of Entrepreneurial Awareness Questionnaire (AEAQ) containing 38 items was developed and used for the study. The scaling responses for the instrument was based on adapted Likert Scale ratings namely: Strongly Agreed (SA) - 5, Agreed (A) - 4, Undecided (U) - 3, Disagreed (D) - 2 and Strongly Disagreed (SD)-1. The reliability of the instrument was determined using Cronbach Alpha coefficient and a coefficient of 0.89 was obtained.

\subsection{Data Collection}

The instruments were personally administered on the respondents by the researchers. Due to adequate monitoring and guidance of the instrument, the whole 22 copies distributed were recovered.

\subsection{Analysis}

The data collected were statistically analysed using descriptive statistics of means and standard deviation as appropriate. A mean of 3.50 and above was considered positive and agreed upon, while a mean rating of less than 3.50 was regarded as negative and disagreed upon.

\section{$3 \quad$ Results}

\subsection{Level of Entrepreneurial Awareness in Mechanical Technology}

The findings on the students' level of entrepreneurial awareness in Mechanical Technology are summarised in Table 1.

Table 1: Mean Scores on level of Entrepreneurial Awareness in Mechanical Technology

\begin{tabular}{|c|c|c|c|}
\hline Attribute & Mean & SD & Remark \\
\hline $\begin{array}{l}\text { Establishment of small and medium scale automobile repair } \\
\text { workshop }\end{array}$ & 4.64 & .58 & Agree \\
\hline Establishment of small and medium scale machine shop & 4.38 & 1.07 & Agree \\
\hline $\begin{array}{l}\text { Establishment of small and medium scale wheel alignment } \\
\text { and balancing enterprise }\end{array}$ & 4.43 & .99 & Agree \\
\hline Establishment of a driving school & 4.06 & 1.09 & Agree \\
\hline $\begin{array}{l}\text { Establishment of small and medium scale welding and } \\
\text { fabrication workshop }\end{array}$ & 4.15 & 1.14 & Agree \\
\hline Establishment of small and medium scale foundry enterprise & 4.24 & 1.13 & Agree \\
\hline Establishment of vocational training centre & 4.00 & 1.18 & Agree \\
\hline
\end{tabular}


The data presented in Table 1 revealed that all the 7 items had a mean range of 4.00 to 4.64 . This indicated that the respondents agreed on all the 7 items on entrepreneurial awareness in Mechanical Technology because their means were above the cut-off point of 3.50. The standard deviation of the items also ranged from .58 to 1.14 . This showed that the respondents were close to one another in their responses.

\subsection{Skills Expected for Entrepreneurship in Mechanical Technology}

Table 2 shows the skills expected for entrepreneurship in Mechanical Technology.

Table 2: Mean Scores on skills expected for entrepreneurship

\begin{tabular}{llll}
\hline Skills & X & SD & Remarks \\
\hline Pedagogical skills in Mechanical Technology & 4.15 & 1.14 & Agree \\
Automobile maintenance, troubleshooting and repairs & 3.55 & 1.31 & Agree \\
Metal machining skills & 3.59 & 1.53 & Agree \\
Metal fitting skills & 3.89 & 1.05 & Agree \\
Metal forging skills & 3.71 & 1.28 & Agree \\
Metal welding and fabrication skills & 3.88 & .98 & Agree \\
Wheel alignment and balancing skills & 3.55 & 1.31 & Agree \\
Automobile driving skills & 3.71 & 1.28 & Agree \\
\hline
\end{tabular}

The data presented in Table 2 revealed that all the 8 items had a mean range of 3.55 to 4.15 . This indicated that the respondents agreed on all the 8 items as skills expected by Technical Education students for entrepreneurship in Mechanical Technology because their means were above the cut-off point of 3.50. The standard deviation of the items also ranged from .98 to 1.31. This showed that the respondents were close to one another in their responses.

\subsection{Facilities Available for Inculcating Entrepreneurial Skills}

The findings on the facilities available for inculcating entrepreneurial skills in the students are summarized in Table 3. 
Table 3: Rating of facilities for inculcating entrepreneurial skills

\begin{tabular}{llll}
\hline Item & X & SD & Remarks \\
\hline Automobile Technology Lecturers & 3.78 & 1.23 & Agree \\
Metalwork Technology Lecturers & 3.66 & 1.28 & Agree \\
Automobile Technologists & 3.89 & 1.14 & Agree \\
Metalwork Technologists & 3.55 & 1.31 & Agree \\
Live vehicle & 3.71 & 1.28 & Agree \\
Dead Vehicle & 3.89 & 1.14 & Agree \\
Lathe Machine & 3.73 & 1.16 & Agree \\
Milling Machine & 3.73 & 1.16 & Agree \\
Shaping Machine & 3.81 & 1.22 & Agree \\
Power Hacksaw & 3.78 & 1.27 & Agree \\
Wheel Balancing/Alignment Machine & 4.15 & 1.14 & Agree \\
On-board Diagnostic Equipment & 4.24 & 1.13 & Agree \\
Welding Machine (Arc) & 3.59 & 1.25 & Agree \\
Oxy-acetylene welding Equipment & 3.66 & 1.28 & Agree \\
Furnaces & 3.83 & 1.11 & Agree \\
Workbenches and Vices & 3.89 & 1.14 & Agree \\
Sets of Spanners & 3.73 & 1.16 & Agree \\
Sets of files & 3.84 & 1.21 & Agree \\
Sets of hammers & 3.81 & 1.22 & Agree \\
Tools for various purposes & 3.78 & 1.27 & Agree \\
Surface planner & 3.89 & 1.05 & Agree \\
Pillar drilling machine & 3.55 & 1.31 & Agree \\
Grinding machine & 3.59 & 1.53 & Agree \\
\hline
\end{tabular}

The data presented in Table 3 revealed that all the 23 items (items 16 to 38) had a mean range of 3.55 to 4.24 . This indicated that the respondents agreed on all the 23 items as facilities available for inculcating entrepreneurship skills in Mechanical Technology because their means were above the cut-off point of 3.50. The standard deviation of the items also ranged from 1.11 to 1.53. This showed that the respondents were close to one another in their responses.

\section{Discussion, Conclusions and Recommendations}

Tables 1, 2 and 3 presented the data analysis for the study. Elisha (2014), corroborated the findings of this study, as he noted that Mechanical Technology is an integral part of Technical Education, which was introduced into the Nigerian education system because of the awareness of its importance and opportunities for jobs creation. Similarly, the findings of this study was also buttressed by Uwaifo (2009) who posited that Technical Education is the 
training of technically oriented personnel who are to be the initiators, facilitators and implementers of technological development of a nation.

The propositions of Elisha (2014), Oputa (2008) and Afeti (2007) were all in consonance with the findings of this study. Elisha (2014) averred that despite the high expectation of the society of mechanical technology graduates to achieve self-reliance, their performance is on the decline. He noted that some of the problems being faced in this area are high cost of tools and equipment needed for setting up metal workshops, hence, a high percentage of metal workshops operate on obsolete tools and equipment, inadequately trained technical instructors, inadequate funds for consumables, and workshop facilities.

Consequently, Oputa (2008) pointed out that functional facilities enable schools and society to achieve their educational goals, while Afeti (2007) stated that, the quality of training in TVE institutions in Nigeria is low with undue emphasis on theory and certification rather than on skills acquisition and proficiency testing. He further noted that inadequate instructor training, obsolete training equipment and lack of instructional materials are some of the factors that combine to reduce the effectiveness of training in meeting the required knowledge and skill objectives.

Hence, the researcher is of the opinion that where adequate facilities are provided, prompt vocational guidance and orientation are initiated, mechanical technology students would avail themselves of the opportunity of being equipped with requisite entrepreneurial skills needed for self-reliance and employment in the global market.

In spite of the enormous potentials in Mechanical Technology aspect of the Technical Education programme, there is need to arouse the curiosity and interest of students to entrepreneurship opportunities posed by the course. Similarly, there is need to applaud the management of Tai Solarin University of Education who provided an enabling environment for acquisition of skills in Mechanical Technology in the University. Therefore, with this applauded gesture, Mechanical Technology students of the University must avail themselves of the available opportunity provided by Tai Solarin University of Education for the acquisition of entrepreneurship skills in Mechanical Technology.

Based on the findings of this study, the study therefore puts the following recommendations forward:

1. Mechanical Technology students of the University must embrace the provided opportunity of the institution and acquire requisite entrepreneurial skills needed for self-reliance.

2. Prompt vocational guidance should be given to students early to be acquitted with necessary entrepreneurship skills in Mechanical Technology. 


\section{References}

Afeti, G. (2007). Strategy to Revitalize Technical and Vocational Education and Training (TVET) in Africa. Meeting of the Bureau of the Conference of Ministers of Education of the African Union (COMEDAF II+). Addis Ababa Ethiopia.

Aminu, A. A (2009) Entrepreneurship Theory \& Practice. Compaq Publishers Limited Maiduguri.

Dyke, L.S., Fischer, E.M., and Reuber, A.R. 1992. An inter-industry examination of the impact of owner experience on firm performance. Journal of Small Business Management. 30(4), 72-87.

Elisha, N.E. (2014). Innovative strategies for enhancing study of mechanical/metalwork technology in Nigerian higher education institutions. International Journal of Scientific Research and Education 2(11), 2391-2399

Lemo, O.O., \& Olakotan, O.O. (2016). Strategies for enhancing the functionality of metalwork workshops in technical and vocational education institutions in Nigeria. Nigeria Journal of Education, Health and Technology Research NJEHETR 8(1), 111-119.

Lidimma, B.G. (2012). Entrepreneurial competencies required by technical college drafting graduates for establishing small and medium scale enterprises in Plateau state. Unpublished M.Ed. Thesis, University of Nigeria, Nsukka.

Nwoye, M.I. (2011). Entrepreneurship development and investment opportunities in Nigeria. Benin: Highcliff Publishers (P. 174).

Oputa, S. (2008). The need for funding Business Education programmes in Nigerian Colleges of Education. Journal of Vocation, Science and Educational Development 8(1): 98-102.

Timmons, J.A. \& Spinelli, S. (2004) New Venture Creation Entrepreneurship for the 21st Century. 6th edition, McGraw-Hill (P.4). 